\title{
Constriction of the Fetal Ductus Arteriosus by Glucocorticoid Hormones
}

\author{
KAZUO MOMMA, ${ }^{(27)}$ SHIGETAKE NISHIHARA, AND YACHIO OTA \\ Section of Pediatric Cardiology, The Heart Institute of Japan, Tokyo Women's Medical College, Tokyo, Japan
}

\begin{abstract}
Summary
Hydrocortisone, prednisolone, and betamethasone were injected into a rat that was 21 days pregnant, and the fetal ductus arteriosus was studied using the rapid whole-body freezing technique. All these glucocorticoids constricted the fetal ductus arteriosus in a dose-dependent relationship. Fetal ductal constriction was maximum 1 to $4 \mathrm{hr}$ after injection and was significantly more prominent in premature fetuses than in mature ones.
\end{abstract}

\section{Speculation}

Glucocorticoids may be useful in constricting the patent ductus arteriosus in the premature babies in place of indomethacin, which is contraindicated in the presence of renal failure or jaundice. Administration of glucocorticoids to the mother may cause fetal ductal constriction and fetal distress.

Recent advances in research on prostaglandins have clarified their physiologic and pharmacologic effects on the fetal and neonatal ductus arteriosus, whereas inhibitors of prostaglandin synthesis such as indomethacin and aspirin have been proved to be effective in treatment of patent ductus arteriosus in the premature baby $(6,7)$. These prostglandin inhibitors, administered to the pregnant animal or directly to the fetus, constricted the fetal ductus arteriosus in experimental animals $(11,18,20)$. The glucocorticoids, another group of drugs which have anti-inflammatory action, have recently been shown to inhibit prostaglandin synthesis through inhibition of the release of prostaglandin precursors such as arachidonic acid $(8,10)$. These actions, which are similar to those of nonsteroidal anti-inflammatory drugs (20), suggest the possibility that glucocorticoids might induce ductal closure. Two clinical observations suggested ductus-constricting effect of glucocorticoids $(5,21)$, but this effect has not been proved definitely yet. For these reasons, we examined the effect of glucocorticoids on the ductus arteriosus of the rat fetus.

\section{MATERIALS AND METHODS}

Wistar rats were raised in separate cages and fed with commercially obtained solid foods. Animals were mated overnight from 3 PM, and vaginal smears were checked at 9 AM the next morning. Pregnancy 0 day was defined by the presence of sperm on vaginal smear.

Time of onset and duration of effect of hydrocortisone sodium hemisuccinate $(125 \mathrm{mg} / \mathrm{ml}$ in distilled water; Japan Upjohn Ltd., Tokyo, Japan), prednisolone acetate $(10 \mathrm{mg} / \mathrm{ml}$ in distilled water; Shionogi Pharmaceutical Co., Tokyo, Japan), and betamethasone disodium phosphate $(2 \mathrm{mg} / \mathrm{ml}$ in distilled water; Shionogi Pharmaceutical $\mathrm{Co}$.) on intrauterine ductal size in the rat was studied as follows. Hydrocortisone $(10 \mathrm{mg} / \mathrm{kg})$, prednisolone $(10 \mathrm{mg} / \mathrm{kg})$, or betamethasone $(0.2 \mathrm{mg} / \mathrm{kg})$ was injected into the dorsum of the thorax of 17 pregnant rats on the 21 st day of gestation. Animals were sacrificed $1,2,4,8$, and $24 \mathrm{hr}$ later by cervical dislocation, and fetuses were delivered quickly by cesarean section and fixed within 5 sec after delivery by the rapid whole-body freezing technique using acetone cooled to $-80^{\circ} \mathrm{C}$ by dry ice (9). Body weight of fetuses was measured in the frozen state to assess fetal maturation. The thorax of the frozen fetus was trimmed and sectioned on the freezing microtome (23) to obtain transverse sections of the main pulmonary artery (PA) and the ductus arteriosus (DA). The inner diameter of these vessels were measured with the binocular microscope (24) and micrometer (25). The inner diameter of the proximal, middle, and distal part of the ductus was measured, and the minimal ductal diameter was divided by the diameter of the main pulmonary artery to get DA/ PA ratio, which was used to determine the effect of glucocorticoids.

Various doses of hydrocortisone (1 to $1000 \mathrm{mg} / \mathrm{kg}$ ), prednisolone $(0.1$ to $1000 \mathrm{mg} / \mathrm{kg})$, and beta methasone $(0.001$ to $100 \mathrm{mg} /$ $\mathrm{kg}$ ) were injected into 27 pregnant rats on the 21 st day of gestation, and the fetal ductal size was studied at $4 \mathrm{hr}$ after injection.

Influence of gestational age on the effect of glucocorticoids on intrauterine ductal size was studied as follows. Hydrocortisone ( 10 $\mathrm{mg} / \mathrm{kg}$ ), prednisolone, or betamethasone was injected into four pregnant rats on the 19th day, and fetal ductal sizes studied $4 \mathrm{hr}$ after injection were compared with those ductal sizes in the experiment on 21 st day of gestation.

Control values were obtained by determining fetal ductal size on the 19th and 21 st day of gestation in two rats who did not receive any medication. Six pregnant rats were allowed to deliver spontaneously on the 21 st or 22 nd day of pregnancy to obtain normal birth weight in the rat. Fetal vitality was checked by observing active movement of the extremities and gasping movement of the jaws just before freezing and microscopic observation of the appearance of a round, unfolded aorta and pulmonary artery on the frozen section of the fetal thorax. Only those animals with vital findings were included in this study. Two-tailed unpaired Student's $t$ test was used for statistical analysis to determine the significance of the difference of mean values.

\section{RESULTS}

Time of onset and duration of effects of hydrocortisone, prednisolone, and betamethasone on fetal ductal size in the rat is shown in Figure 1. Fetal ductal constriction began in the first hr after injection in all glucocorticoids $(P<0.05)$. Maximum fetal ductal constriction occurred at 1 to $4 \mathrm{hr}$ after injection of hydrocortisone, at $2 \mathrm{hr}$ after injection of prednisolone, and at $4 \mathrm{hr}$ after injection of betamethasone. Mild but significant $(P<0.05)$ ductal constriction persisted at $24 \mathrm{hr}$ after injection of each glucocorticoids.

The effects of various doses of hydrocortisone, prednisolone, and betamethasone on fetal ductal size in the rat are shown in Figure 2. These dose-effect curves showed that a massive dose of each glucocorticoid resulted in complete constriction of the fetal ductus arteriosus. Relative potency of the ductus-constricting effect of hydrocortisone, prednisolone, and betamethasone was roughly $1: 2: 20$. Vital signs, behavior, and activity of the rat and fetus were unchanged after injection of each glucocorticoid except for one rat which became dyspneic and collapsed at $4 \mathrm{hr}$ after 


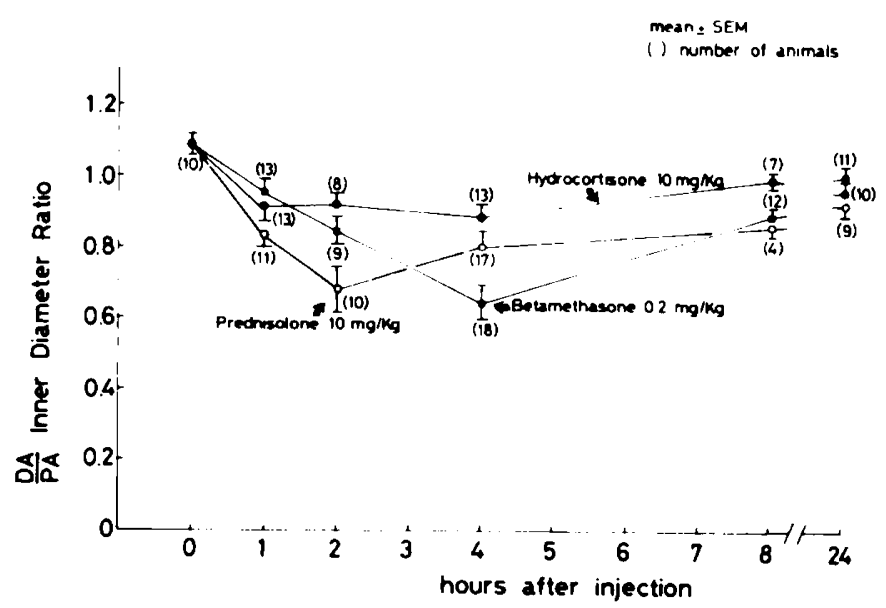

Fig. 1. Time of onset and duration of effect of hydrocortisone $(10 \mathrm{mg} /$ $\mathrm{kg}$ ), prednisolone $(10 \mathrm{mg} / \mathrm{kg})$, or betamethasone $(0.2 \mathrm{mg} / \mathrm{kg})$ on the fetal ductus arteriosus in the rat. DA/PA, ductus arteriosus/main pulmonary artery.

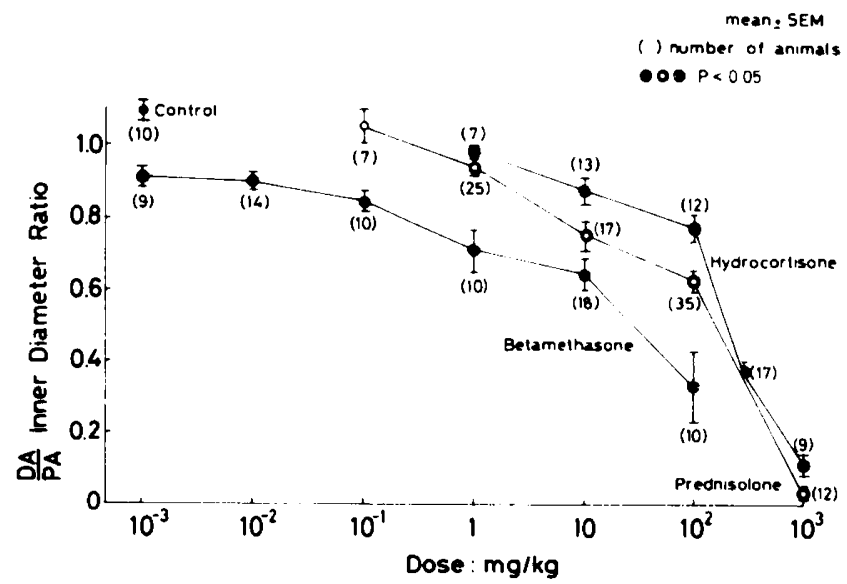

Fig. 2. Effect of various doses of hydrocortisone, prednosolone, and betamethasone on fetal ductus arteriosus in the rat. DA/PA. ductus arteriosus/main pulmonary artery.

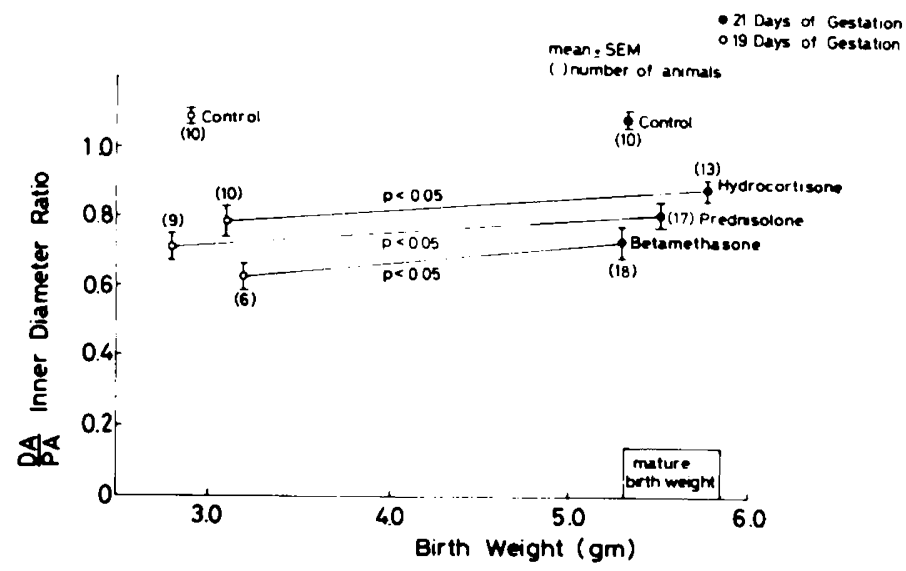

Fig. 3. Influence of gestational age on the effect of glucocorticoids on fetal ductus arteriosus in the rat. Comparison of effects of $10 \mathrm{mg} / \mathrm{kg}$ of hydrocortisone, prednisolone, or betamethasone in preterm rats of 19 days gestation and in term rats of 21 days. DA/PA, ductus arteriosus/main pulmonary artery.

injection of prednisolone $(1000 \mathrm{mg} / \mathrm{kg})$. Three of 15 littermates from this rat showed failing vital signs, and the remaining littermates showed completely closed ductus. No increased mortality of fetuses were observed in other procedures.
Influence of gestational age on the effect of hydrocortisone. prednisolone, and betamethasone on fetal ductal size in the rat is shown in Figure 3. Each glucocorticoid showed stronger ductal constriction in premature fetuses of the 19th day of gestation than in mature ones, and these differences were statistically significant $(P<0.05)$

\section{DISCUSSION}

The present study shows that glucocorticoids administered to the pregnant rat constricts the fetal ductus arteriosus. Glucocorticoids administered to the pregnant rat transfer through the placenta to the fetus (17). The mechanism of ductal constriction in the fetus in response to glucocorticoids is not clear, but presumably is due to inhibition of phospholipase $A_{2}$, thereby inhibiting release of arachidonic acid and formation of prostaglandins $(8,14,20)$. Alteration of steps further along also could play a role. Inhibition of fetal prostaglandin formation by administration of indomethacin or acetylsalicylic acid to the pregnant animal causes constriction of the fetal ductus arteriosus (11, 16, 18). The greater constricting effect of corticosteroids in the less mature animal is similar to that described for indomethacin and fetal lamb (2). Clyman et al. (3) showed that the ductus of the immature fetal lamb is more sensitive to the dilating action of prostaglandins than the ductus of the mature fetal lamb. These comparable results are compatible with the hypothesis that ductus-constricting effects of glucocorticoids are due to inhibition of prostaglandin formation in the fetus.

Glucocorticoids have been used to accelerate maturation of the fetal lung and to prevent hyaline membrane disease $(1,12,18$, 19). For this purpose betamethasone $(0.2 \mathrm{mg} / \mathrm{kg})$ or the same dose of dexamethasone was injected intramuscularly to pregnant women with premature labor $(12,15,19)$. Our present study shows that such treatment may cause fetal ductal constriction and possibly some fetal distress. One clinical report has demonstrated increased fetal death and distress, as well as placental insufficiency in the offspring of mothers who received prednisolone therapy during pregnancy (22), although such results have not been observed by others. Further careful study is needed to clarify the possible effect on the fetal circulation $(4,13)$.

The present study suggests that glucocorticoids may be useful to close the patent ductus arteriosus in clinical situations. At the present time, indomethacin is used to treat the premature baby with patent ductus arteriosus, congestive heart failure, and respiratory distress syndrome. In some situations, such as in the presence of renal failure or jaundice, indomethacin is contraindicated. and glucocorticoids might be safely used in its place. The duration of the effect of glucocorticoids is shorter than that of indomethacin, and more frequent administration is necessary. Glucocorticoids may induce harmful effects such as decreased resistance to infection, disturbance of plasma electrolites, or hypertension. The dose of glucocorticoids remains to be determined. Although massive doses of glucocorticoids are needed to constrict the fetal ductus completely in this study, a smaller dose might be sufficient to constrict the ductus arteriosus if these glucocorticoids were administered directly to the baby.

\section{CONCLUSION}

Glucocorticoids constrict the ductus arteriosus of the rat fetus. This effect is dose dependent. Ductus constricting potency ratio of hydrocortisone, prednisolone, and betamethasone is approximately 1:2:20. Fetal ductus arteriosus constricts and closes completely if glucocorticoids are injected into the pregnant rat in massive dosage. The effect is maximal 1 to $4 \mathrm{hr}$ after injection and persists more than $24 \mathrm{hr}$. Ductus-constricting effect of glucocorticoids is more potent on premature fetuses than on mature ones.

\section{REFERENCES AND NOTES}

1. Ballard. P. L.: Glucocorticoids and respiratory distress syndrome: status 1979. Pediatrics, 63: 163 (1979).

2. Clyman, R. I.: Developmental responses to oxygen, arachidonic acid, and indo- 
methacin in the fetal lamb ductus arteriosus in vitro. Prostaglandins Med., I: 167 (1978)

3. Clyman, R. I.. Mauray, F.. Rudolph. A. M.. and Heymann. M. A.: Age-dependent sensitivity of the lamb ductus arteriosus to indomethacin and prostaglandins. J. Pediatr., 96: 94 (1980)

4. Csaba. I. F., Sulyok. E., and Ertl. T.: Relationship of maternal treatment with indomethacin to persistence of fetal circulation syndrome. J. Pediatr.. 92: 484 (1978).

5. Emmanouilides (j. C: (personal communication)

6. Friedman. W. F., Hirschklau. M. J.. Printz, M. P. Pitlick. P. T.. and Kirkpatrick. S. E.: Pharmacological closure of patent ductus arteriosus in the premature infant. N. Engl. J. Med.. 245: 526 (1976).

7. Heymann. M. A., Rudolph, A. M., and Silverman, M. H.: Closure of the ductus arteriosus in premature infants by inhibition of prostaglandin synthesis. $\mathrm{N}$ Engl. J. Med., 295: 530 (1976).

8. Hong. S-C. L., and Lewis, L.: Inhibition of arachidonic acid release from cells as the biochemical action of anti-inflammatory corticosteroid. Proc. Natl. Acad S.i. U. S. A.. 73: 1730 (1976).

9. Hornblad, P. Y.. and Larsson, K. S.: Studies on closure of the ductus arteriosus 1. Whole-body freezing as improvement of tixation procedure. Cardiologia, $5 /$ : 231 (1967).

10. Kantrowitz. F.. Robinson, D. R.. and McGuire. M. B.: ('orticosteroids inhibi prostaglandin production by rheumatoid synovia. Nature (Lond.). 258: 737 (1975).

11. Levin. D. L., Mills, L. J., Parkey. M.. Garriott, J., and Cambell, W.: Constriction of the fetal ductus arteriosus after administration of indomethacin to the pregnant ewe. J. Pediatr., 94: 647 (1979).

12. Liggins, G. C . and Hawie. R. N.: A controlled trial of antepartum glucocorticoid treatment of the respiratory distress syndrome in premature infants. Pediatrics. 50): $515(1972)$

13. Manchester, D.. Margolis, H. S., and Sheldon. R. E.: Possible association between maternal indomethacin therapy and primary pulmonary hypertension of the newborn. Am. J. Obstet. (jynecol.. 126: 467 (1976).

14. Nijkamp. E. P.. Flower. R. J.. Moncada. S.. and Vane. J. R.: Partial purification of rabbit aorta contracting substance-releasing factor and inhibition of its activity by antiintlammatory steroid. Nature (Lond.). 26.3: 479 (1976).

15. Papageorgiou. A. N.. Desgranges, M. F.. Masson. M. Cole. E., Shatz. R.. and

Copyright (C) 1981 International Pediatric Research Foundation. Inc $0031-3998 / 81 / 1501-0019 \$ 02.00 / 0$
Gelfand. M. M.: The antenatal use of betamethasone in the prevention of respiratory distress syndrome: a controlled double-blind study. Pediatrics, 62: 73 (1979)

16. Rudolph. A. M., and Heymann, M. A.: Hemodynamic changes induced by blockers of prostaglandin synthesis in the tetal lamb in utero. In: F. Coceani. P. M. Olley: Advances in Prostaglandin and Thromboxane Research. Vol. 4. p. 231 (Raven Press. New York. 1978).

17. Shardein, J. L.: Drugs as teratogens. p. 217 (CRC Press. (leveland, OH. 1976).

18. Sharpe. G. E.. Larsson, K. S.. and Thalme, B.: Studies on closure of the ductus arteriosus. XII In utero effect of indomethacin and sodium salicylate in rats and rabbits. Prostaglandins, 9: 585 (1975).

19. Taeusch, H. W., Jr., Frigoletto. F.. Kitzmiller. J., Avery. M. E., Hehre. H.. Fromm. B. Lawson. E., and Neff. R. K.: Risk of respiratory distress syndrome after prenata! dexamethasone treatment. Pediatrics, 6.3: 64 (1974)

20. Vane, J. R.: Inhibitions of prostaglandin, prostacyclin, and thromboxane synthesis. In: F. Coceani, P. M. Olley: Advances in Prostaglandin and Thromboxane Research. Vol. 4, p. 27 (Raven Press, New York, 1978)

21. Waffarn, F., Siassi, B., Schmidt, P., Cabal, L., and Hodgman. J. E.: The association of antenatal glucocorticoid administration and ratent ductus arteriosus in the preterm infant. Pediatr. Res., 14: 353 (1979).

22. Warrell. D. W.. and Taylor, R.: Outcome for the fetus of mothers receiving prednisolone during pregnancy. Lancet, 1: 117 (1968).

23. Freezing Microtome. Komatsu Solidate Co.. Tokyo, Japan.

24. Nikon Binocular Stereoscopic Microscope. Nihon-Kogaku Co., Tokyo, Japan

25. Nikon Ocular Micrometer, Nihon-Kogaku Co., Tokyo, Japan.

26. Editorial help of Drs. L. M. Linde. Clinical Professor of Pediatric Cardiology. University of California, Los Angeles, and T. A. Riemenschneider, Protessor of Cardiovascular Pediatrics, University of California. Davis, is highly appreciated.

27. Requests for reprints should be addressed to: Kazuo Momma, M.D.. The Hear Institute of Japan. Tokyo Women's Medical College, Kawada-cho 10, Shinjukuku, Tokyo, Japan.

28. This research was supported by Japan Research Promotion Society for Cardiovascular Diseases and by a grant in aid for scientific research from the Ministry of Education. Science. and Culture of Japan.

29. Received for publication January 7,1980

30. Accepted for publication June 4. 1980. 